\title{
Quality assurance and control system for railway track tamping
}

\author{
Andrey Ilinykh ${ }^{1, *}$, Alexey Manakov ${ }^{1}$, Andrey Abramov ${ }^{1}$, and Sergey Kolarzh ${ }^{1}$ \\ ${ }^{1}$ Siberian Transport University, 630049 Novosibirsk, Russia
}

\begin{abstract}
Ensuring stable parameters of a railway track after bringing it into a design position is a key measure of quality for evaluating completed repairs. Identifying quality criteria for sleeper tamping using a special rolling stock is a high-priority problem for a railway track infrastructure. This problem is complicated by a large choice of ballast compaction, leveling and finishing machines, totaling more than 30 types. The paper presents results of theoretical studies aimed at assuring and controlling the quality of tamping by multi-purpose track machines. The factors that determine the stability of railway track parameters in operation were identified. The track repair processes were analyzed. The operating factors that are essential for developing qualitative process parameters were identified for various types of track machines. Based on the findings of these studies, a quality assurance and control methodology was developed for railway track repair and maintenance operations.
\end{abstract}

\section{Introduction}

During operation of a railroad track, assembled rails and sleepers are under train loads, which are transferred to the ballast layer and cause its elastic and permanent deformations. Over time, deformations are accumulated and, as a rule, unevenly distributed along the track length. The stability of a repaired railway track is determined by resistance of sleepers to longitudinal and lateral shifts, as well as by track settlement, and depends mainly on the quality of two operations: track leveling and tamping [1].

The quality of leveling is determined by requirements for the accuracy of positioning a railway track in terms of level, longitudinal section and plan. Quantitative values of these requirements are established and determined by applicable technical regulations [2-3]. They are used in designing instrumentation systems, track leveling devices and automation equipment of track machines. These parameters can be monitored during the operation of track leveling, tamping and lining machines (track renewal trains), thereby controlling the quality of work.

The quality of track tamping is primarily determined by the degree of ballast compaction under sleepers, which should be sufficient not only to hold assembled rails and sleepers in a leveled position, but also to ensure their stability in further operation. Recommended degrees of ballast compaction were established through modeling [4-6] and confirmed by a number of experimental studies [7-8]. According to these studies, a

\footnotetext{
* Corresponding author: asi80@ngs.ru
} 
necessary and sufficient degree of compaction for ballast thickness $H$ will be reached if the relative settlement of the layer is $E \geq(0.15 \div 0.17) H$.

As shown by field tests of tracks [9], even modern track machines with their capacity and operating speed can ensure only $\mathrm{E}=(0.11 \div 0.13) \mathrm{H}$. First of all, this suggests that selected operating modes of tamping machines are inefficient and not controlled in operation. At present, these parameters cannot be monitored during operation of machines due to the lack of monitoring techniques and appropriate instruments. Another important factor that makes it difficult to assure the quality of track tamping is a dependence of degree of ballast compaction on such factors as ballast contamination and porosity, height to which a track is raised, and ballast thickness. These factors lead to a scientific problem that has not been solved yet: a constant change in the density of a ballast section due to a change in its structure. These changes do not allow using a generally accepted indicator for estimating the quality of tamping - relative ballast settlement $E$.

Scientists have proposed various solutions to this problem, e. g. adding polyurethane fillers [10] or rubber crumb [11] to ballast, or stabilizing the ballast section with a geogrid [12]. All these solutions have not come into wide use due to the complexity and high cost of related technologies. The greatest effect can be achieved by establishing the dependence of changes in the ballast structure and density on vibration parameters.

The purpose of the presented theoretical research is to determine the dependence of quality indicators of ballast compaction on the operating factors of tamping machines in different operating conditions. The theoretical research results can be used to address a high-priority problem of the railway track infrastructure - to develop a quality assurance and control methodology, as well as related tools for track tamping.

\section{Theoretical data}

\subsection{Physical basis of stone ballast compaction}

The initial stage of ballast operation under load corresponds to the stabilization period $T_{1}$. By the end of this period, a stabilized ballast state is achieved, and the ballast section becomes capable to take operational loads for a long time. In this phase, the current state of ballast is characterized by relative settlement $E_{Y}$, which does not exceed its limit value $E_{n}$.

As soon as the ballast reaches the limit state $\left(E_{Y} \approx E_{n}\right)$, it completely loses the ability to be compacted, while achieving the maximum bearing capacity. If a load on the ballast section does not exceed the limit values, it remains stable for a long time, thereby moving to a steady flow stage $T_{2}[13]$.

The third ground flow stage $T_{3}$ is a stage of destruction [13]. First, the accumulation rate of plastic deformations is increased without significantly destructing the ballast body (prerepair period). This process is followed by viscous destruction of the ballast body and a rapid loss of its bearing capacity.

Let us consider a stone ballast layer, which, at the initial time point, has a thickness $H_{H}$. As a result of force action, a new thickness of the compacted layer becomes equal to $H_{Y}$. The state of the ballast layer to and prior compaction can be characterized by settlement parameters $\Delta H_{H}$ and $\Delta H_{Y}$. If we assume that the ultimate loose state of the ballast layer is characterized by thickness $H_{0}$, its relative settlement for the initial and compacted states, respectively, will be determined by the following relations:

$$
E_{H}=\frac{\Delta H_{H}}{H_{0}}=\frac{\Delta V_{H}}{V_{0}} ; E_{Y}=\frac{\Delta H_{Y}}{H_{0}}=\frac{\Delta V_{Y}}{V_{0}},
$$


where $\Delta V_{H}, \Delta V_{Y}$ is the decrease in the ballast volume before and after its compaction from the ultimate loose state; $V_{0}$ is the ballast volume in the ultimate loose state assumed as the base.

The ballast layer is transformed from the pre-compacted state to the compacted state by tamping padding techniques. It can be said that the track machine "adds" the following value to the relative layer settlement:

$$
E_{M}=\frac{\Delta H_{Y}-\Delta H_{H}}{H_{0}}=\frac{\Delta V_{Y}-\Delta V_{H}}{V_{0}}=E_{Y}-E_{H} .
$$

In other words, the relative track settlement is an additive value since it is accumulated and determined relative to the same base state.

The relative settlement can be estimated not only through the ratio between ballast volumes in various states (i.e. at the macro level), but also at the level of particles interacting with each other. For this purpose, two parameters are used: porosity $n$ and void ratio $\varepsilon$.

$$
n=\frac{V_{n}}{V_{c}+V_{n}} ; e=\frac{V_{n}}{V_{c}}
$$

where $V_{c}$ is the volume of crushed stone filled with grains, $\mathrm{m}^{3} ; V_{n}$ is the volume of crushed stone filled with air, $\mathrm{m}^{3}$.

These two indicators of stone compaction can be connected to each other by the following relations:

$$
\begin{gathered}
\varepsilon_{Y}=\frac{n_{Y}}{1-n_{Y}}=\frac{\rho_{c}}{\rho_{Y}-1}=\varepsilon_{0}\left(1-E_{Y}\right)-E_{Y}=\frac{n_{0}-E_{Y}}{1-n_{0}} ; \\
E_{Y}=\frac{\Delta V_{Y}}{V_{0}}=\frac{\varepsilon_{0}-\varepsilon_{Y}}{1+\varepsilon_{0}},
\end{gathered}
$$

where $\varepsilon_{0}, \varepsilon_{Y}$ are void ratios of crushed stone in ultimate loose and compacted states, respectively; $n_{0}, n_{Y}$ are porosities of crushed stone in ultimate loose and compacted states, respectively; $\rho_{c}, \rho_{Y}$ are the density of the material of particles and bulk density of the compacted crushed stone, respectively.

The formulas (1) ... (5) show that the quality of ballast tamping can be estimated by two key indicators: the void ratio $\varepsilon$ and the relative ballast settlement $E$. According to GOST [14], the porosity of crushed stone is $n_{0}=0.42 \div 0.45$ in the ultimate loose state and $n_{n}=0.36 \div 0.37$ in the ultimate compacted state. The void ratios calculated by the formulas (4) and (5) are $\varepsilon_{0}=0.724 \div 0.818$ in the ultimate loose state and $\varepsilon_{n}=0.563 \div 0.587$ in the ultimate compacted state. Thus, the relative settlement of the crushed stone ballast in the ultimate compacted state is $E_{n}=0.18 \div 0.25$.

\subsection{Quality indicators of stone ballast compaction}

Since there is an ultimate compacted state of the ballast $E_{n}$, its stabilization process can be modeled through saturation of the compaction indicator accepted for consideration relative settlement $E_{Y}$. The accumulation of the relative ballast settlement $E_{Y}$ can be described by the following expression: 


$$
E_{Y}=E_{H}+\frac{E_{n}}{\sqrt{1+\left(\frac{E_{n}}{K_{E} T}\right)^{2}}},
$$

where $E_{H}$ is the initial relative settlement of the ballast obtained by static compression (in our case, it occurs under the load of wheelsets of tamping machines in operation); $E_{n}$ is the ultimate relative settlement for a specific force action; $K_{E}$ is the rate of rise of the relative settlement from the beginning of the force action; $T$ is the load integrally accumulated by the ballast during the cyclic action of the vibrating surface, $\mathrm{kPa}$ :

$$
T=\frac{\omega t}{2 \pi} \sum_{i=1}^{m} p_{i}
$$

where $\omega$ is the angular vibrational frequency, $\mathrm{rad} / \mathrm{s} ; t$ is the time of action of the vibrating surface on the ballast, $\mathrm{s} ; i$ are cycles of oscillations $(i=1,2, \ldots, m)$.

In each compression cycle, the ballast is elastically deformed and accumulates inelastic deformations. Under the influence of inelastic deformations, the structure becomes more ordered and concentrated. In the next cycle, it is necessary to apply more pressure to cause inelastic deformation. The ultimate pressure $(\mathrm{kPa})$ at which the ballast material begins to deform inelastically can be calculated by the following formula:

$$
p=q \cdot|\ln (2 \varepsilon-1)|
$$

where $\varepsilon$ is the void ratio of the ballast; $q$ is the experimental coefficient $\left(q_{0}=(0.3 \div 0.5) \cdot 10^{3}\right.$ $\mathrm{kPa}$ for the loose ballast; $q_{n}=(0.6 \div 0.8) \cdot 10^{3} \mathrm{kPa}$ for the compacted ballast. At $\varepsilon>0.5$, intermediate values of the coefficient $q$ can be determined by linear interpolation.

The rise of the bearing capacity will be limited to the maximum pressure $p_{\max }$ that can be reached by the vibrating surface of the machine, and the ultimate relative settlement of the ballast $E_{n}$. If $p_{\max }<p_{n}\left(p_{n}\right.$ is the pressure $(\mathrm{kPa})$ above which the ballast structure is destroyed, then the relative settlement of the compacted ballast will be $E_{Y}<E_{n}$, and no further compression will occur. This means that the ballast layer can take this load, while being elastically deformed.

\subsection{Performance of tamping machines}

The number of vibration actions $N$ on a compacted material can be used as an indirect indicator of the achieved degree of ballast compaction.

$$
N=v t
$$

where $v$ is the oscillation frequency of the working tool, Hz.

Regardless of a design of tamping tools used in leveling and tamping machines, they process the ballast in the same way - by compacting the material through vibratory impact. The experimental data [15] show that, on average, the most intensive ballast compaction takes place in the first 3-4 seconds in cyclic machines and 5-6 seconds in continuous machines. Then the process begins to decay.

It should be noted that, even with the same number of vibration actions, the degree of compaction may vary. The greatest effect is achieved at certain values of vibratory tamping parameters, which are characterized by the coefficient $K[16]$ : 


$$
K=\frac{v_{o}}{2 \pi v A},
$$

where $v_{o}$ is the ballast compaction rate, $\mathrm{mm} / \mathrm{s} ; A$ is the oscillation amplitude of the working tool, $\mathrm{mm}$.

If $K=0.08 \div 0.12$, the working tool has an effective vibratory impact on the material to be compacted during the oscillation period. This is explained by the fact that, being redistributed more efficiently, ballast grains are moved to a more stable position, and as a result, a track becomes more stable as well.

At $K>0.12$, the interaction of the working tool with the ballast changes significantly. Vibrocompression of the material takes place. As shown by studies [15-16], the degree of ballast compaction caused by this action is significantly lower as compared to vibratory impact.

Even if the efficient operating mode is chosen for cyclic leveling and tamping machines, their productivity is reduced by at least 1.5 times. In order to improve the quality of sleeper tamping, the double ballast compaction technique is used in practice, which also leads to a decrease in the productivity of these machines.

Thus, operators always face a dilemma: either to choose high productivity of machines and poor quality of sleeper tamping, or conversely: to ensure a stable track condition after repair while performing less work in the same time.

\subsection{Setting objectives for developing the quality assurance and control system for ballast tamping}

The theoretical framework of stone ballast compaction considered above shows that force actions on the ballast generate some multifactorial processes. Parameters of these processes are usually stochastic and difficult to describe by mathematical models.

By analyzing the methods and designs of working tools used in sleeper tamping, the following should be noted. In their efforts to improve working members, as well as leveling and tamping processes, engineers have almost exhausted the possibilities of improving a combination of performance characteristics, such as the quality of sleeper tamping and high productivity. Therefore, it is very important to use working tools with efficient vibratory tamping parameters on all types of machines and to follow operating procedures.

When choosing operating modes for leveling and tamping machines, it is necessary to take into account such parameters as the actual state of the ballast layer, types and number of machines used, and a sequence of their operations. In order to assure the quality of ballast tamping, it is necessary to check operating modes of leveling and tamping machines, first of all, ballast compaction rate, oscillation frequency of the working tool, and the duration of vibration action.

\section{Quality assurance and control system for ballast tamping}

According to the objectives set above, the quality assurance and control system for ballast tamping was developed on the basis of the existing software and hardware system "Status Monitoring System", designed for acceptance control of track machines after maintenance and repair, and remote status monitoring of track equipment in operation. The Status Monitoring System includes calibrated and certified instruments that can measure technical parameters of track machines with high accuracy. A set of sensors can be configured and expanded, thereby making it possible to select the necessary range of parameters measured by the system. The Status Monitoring System is equipped with a $3 \mathrm{G}$ module designed for real-time remote transmission of measured parameters [17-19]. 
Quality of track tamping is controlled using performance assessment tools for track equipment. The Status Monitoring System is based on a relationship between performance parameters of track machines and track stability parameters, shown in Figure 1.

Performance parameters of track machines are monitored by a set of sensors. The number of sensors depends on a range of monitoring tasks. During this study, it has been found that at least three parameters should be monitored for the purposes of quality control: ballast vibrocompression rate, oscillation frequency of the working tool, and the duration of vibration action.

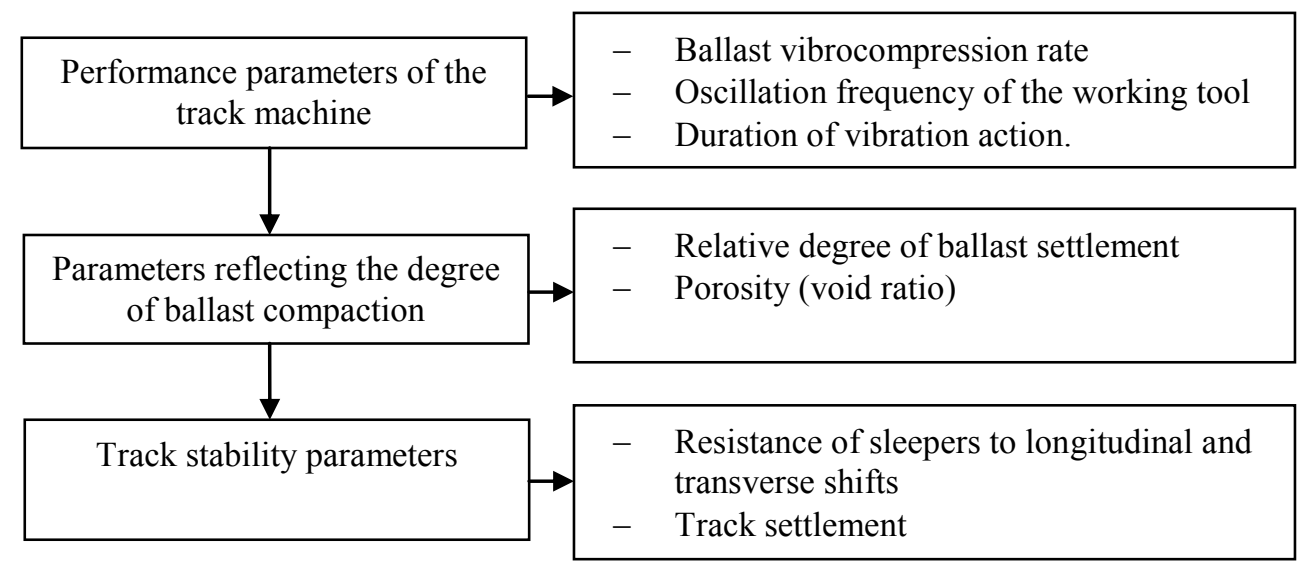

Fig. 1. Relationship between performance parameters of tamping machines and track stability parameters.

The tamping quality control system was tested in real conditions using Duomatic 09-32 track machine at one of linear facilities of the Ural Track Machine Operations Directorate. During the operation of the machine, vibration parameters were read from the sensors installed on tamping units and then compared with the required values calculated from the relations (6)-(10). Further, the parameters of actual ballast settlement and ballast density were estimated and compared with the required values. The difference varied from 8 to $26 \%$.

\section{Conclusion}

Based on the theoretical research, a dependence of changes in the ballast structure and density on vibration parameters was established. The practical test showed that these dependencies can be used to designate operating modes of tamping machines in order to provide the necessary quality indicators for ballast compaction. The accuracy of results depends mainly on how accurately the initial state of a ballast layer is determined.

As a result of the research, the authors developed a theoretical framework that can be used to develop a software and hardware system for remote quality control of track operations. Widespread adoption of this system will significantly reduce maintenance cycles of railway tracks by maximizing the track stability.

Determining ballast compaction parameters for various track operating conditions remains an open question and needs to be further studied. Thus, the further development of this research area should be aimed at determining the necessary density and structure of the ballast layer in different track operating conditions to ensure its maximum stability. 


\section{References}

1. B. Indraratna, H. Khabbaz, W. Salim, D. Christie, Ground Improvement, 3, 91-101 (2006).

2. STN C 01-95. Zheleznye dorogi kolei $1520 \mathrm{~mm}$ [Railways with gauge $1520 \mathrm{~mm}$ ] (Ministry of Railways of Russian Federation, Moscow, 1995). (in Russian)

3. Tehnicheskie uslovija na raboty po remontu i planovo-predupreditel'noj vypravke puti [Technical specifications on repair works and preventive maintenance of the track] (Moscow, 2003). (in Russian)

4. M. Lu, PhD thesis, University of Nottingham, 2008.

5. N. Trung Ngo, B. Indraratna, C. Rujikiatkamjorn, Computers and Geotechnics, 55 (January), 224-231 (2014).

6. B. Indraratna, Li-Jun Su, C. Rujikiatkamjorn, Canadian Geotechnical Journal, (February), 322-326 (2011).

7. S. Lobo-Guerrero, L.E. Vallejo, Granular Matter, 8, 195-204 (2006).

8. B. Indraratna, F. Asce; S. Nimbalkar, D. Christie, C. Rujikiatkamjorn, J. Vinod, Journal of Geotechnical and Geoenvironmental engineering, (July), 907-917 (2010).

9. M.E. Bona, The effect of straightening and grinding of welds on track roughness, QUT Thesis (Masters by Research), Queensland University of Technology, 16180, (2017).

10. A. Keene, J. Tinjum, T. Edil, Geotechnical Engineering Journal of the SEAGS \& AGSSEA, Vol. 45, 1 (March), 67-73 (2014).

11. M. Sol-Sanchez, N. Thom, F. Moreno-Navarro, M. Rubio-Gamez, G. Airey, Construction and Building Materials, 75, 19-24 (2015).

12. B. Leshchinsky, Geo-Frontiers, ASCE 2011, 4693-4702 (2011).

13. B. Indraratna, S. Nimbalkar, D Christie, The performance of rail track incorporating the effects of ballast breakage, confining pressure and geosynthetics reinforcement, 8th International Conference on the Bearing Capacity of Roads, Railways, and Airfields, London, 5-24 (2009).

14. GOST 7392-2002. Crushed stone of solid rocks for railway ballast. Specifications (Standartinform, Moscow, 2002). (in Russian)

15. G.P. Zadorin, Railway Track and Facilities, 11, 22-24 (2007). (in Russian)

16. V.M. Popovich, V.M. Bugaenko, Putevye mashiny [track machine] (Zheldorizdat, Moscow, 2007). (in Russian)

17. A.L. Manakov, S.A. Kolarzh, Transport of the Urals, 1(52), 57 - 60 (2017). (in Russian)

18. N.A. Maslov, Chief Mechanical Engineer, 12, 27-34 (2016). (in Russian)

19. A.D. Abramov, N.A. Maslov, Chief Mechanical Engineer, 10, 48-53 (2015). (in Russian) 